\title{
I Tax You Tax; Quality of Life and Self Taxation
}

\author{
Ryan M. Yonk ${ }^{1}$ \\ ${ }^{1}$ Department of Political Science, Southern Utah University, Cedar City, Utah, USA \\ Correspondence: Ryan M. Yonk, 351 West Universtiy Blvd GC406, Cedar City, Utah 84720, USA. Tel: \\ 1-435-586-7961. E-mail: ryanyonk@suu.edu
}

Received: March 22, 2013 Accepted: April 23, 2013 Online Published: September 30, 2013

doi:10.5539/par.v2n2p174 URL: http://dx.doi.org/10.5539/par.v2n2p174

\begin{abstract}
Citizens are occasionally asked to make specific policy decisions that elected officials are either unable or unwilling to make directly. Among the most common policies where specific voter approval is sought is the leveling of new taxes at the local level. I find that the quality of life of local communities is used by voters in deciding whether to support local tax increases.
\end{abstract}

Keywords: tax policy, quality of life, direct democracy, voting, taxation, local government

\section{Introduction}

Citizens are occasionally asked to make specific policy decisions that elected officials are either unable or unwilling to make directly. Among the most common policies where specific voter approval is sought is the leveling of new taxes at the local level. Much has been made of the inability of citizens to make clearly rational decisions when faced with simple survey questions. (Campbell, Converse, Miller, \& Stokes, 1960) If this view of the inability of citizens is correct, what does the average voter do when asked to make a decision about a specific policy issue?

If citizens are simply guessing when making these decisions finding consistent patterns that relate to theoretically important variables should be nearly impossible. It is these patterns that the political scientist seeks to find, validate, and test empirically. This study is no different, I identify a specific pattern that has the theoretic ability to explain how citizens decide tax issues placed before them on the ballot, and using election results from two hundred and twenty two counties, I test whether a discernible pattern of decision making can be identified.

\section{How decisions get made:}

Determining how members of the public develop and maintain opinions about political issues is a topic that has been hotly discussed. Despite the lack of information by many in the that lack does not prevent them from indicating preferences on policy issues, especially when asked to vote on policy outcomes. Citizens can identify what they dislike, if not why they dislike it, in short they have opinions. This understanding matches the literature's assertions about individual information processing, how information is used in making decisions, and how preferred policy outcomes are identified.

One theory asserts that voters who lack information are unable or unlikely to gain information and therefore answer policy questions in a way that is little better than random guessing. (Converse, 1964) As evidence Converse and others highlight a tendency of respondents to answer policy questions even when they lack specific information about the policy in question. (Campbell, Converse, Miller, \& Stokes, 1960) These authors laid the groundwork for exploring why respondents answer in this way, and how respondents reach conclusions without all the information. A review of the literature, however, makes it apparent that something more than random guessing is occurring; respondents are utilizing decision strategies that draw on the limited information they have to answer questions when asked (Popkin, 1991). The use of information by individuals when considering public policy, begs the question of how that information is used and what influences its use.

John Zaller (1992) in, "The Nature and Origins of Mass Opinion”, proposes that individuals form opinions based on pieces of information that have become salient in their daily activities. As they are faced with situations where decision making is necessary they draw on the information that is available. Decisions are made and information is used based on prior experience, saliency, heuristic value, and other factors that push information in an individual's active consideration. This model of decision making, unlike Converses assertion that individuals are merely 
guessing, or are minimally using information as suggested by Popkin, is supplanted by information intensive processes where the individuals rely on a relatively large amount of information to make decisions. The reception and acquisition of that information by an individual is paramount in this model. Zaller's model of how information is gathered, received, and evaluated on an individual basis asserts that information is received, considered in light of other information, and filed away for future consideration. Thus the individual faces a similar situation when the information is available, as they consider how to respond to the new situation.

Working from a Zaller-esque model, which asserts that previous information should have an effect on future decision-making, some have proposed that rather than simply retaining all of the necessary information, individuals utilize heuristic devices which allow them to interact with the relatively large amount of previous information in a way that is both systematic, and parsimonious. Given the relatively large set of studies including several of those already discussed which call into question the ability of individuals to retain even relatively small amounts of information these heuristic devices are of particular importance.

The importance and the ability of heuristic devices to achieve this goal and improve the use of information, has been widely tested. While the results of these tests have been mixed, (Kuklinski, \& Quirk, 2001) they do however provide some basis for believing that if the heuristic that voters use is correct, strong enough to override other information, is providing the correct information, and is applied in the proper context, it can lead citizens to use information both parsimoniously and systematically to reach the correct outcome (Lupia, 1994).

Given the potential of heuristic devices to provide citizens with a relatively low cost decision making strategy, the question that immediately arises is what is the correct heuristic device? Again the literature has provided a plethora of potential options. These options have can be understood first, as types of processes that can be used to reach decisions, and second (Lau \& Redlawsk, 2006) specific cues and cue-givers that provide the information necessary within those processes (Rahn, 1993; Taber \& Lodge, 2006; Goren, 2005).

Understanding the basics of the processes is important to any study that attempts to consider how citizens make political decisions, particularly when those decisions are specific policy choices presented at the ballot box. Using Lau and Redlawsk's (1997) basic divisions to consider these processes and some of the specific heuristic devices that are brought to bear in their use, provides information about how political decisions are reached.

The first potential strategy, which while not a true heuristic device per se, is important as the remaining strategies deviate from it; is simply the use of memory, this approach has alternatively referred to as rationality or rational choice decision making. Citizen's sort and store specific information about particular policies for use in the future, and retrieve and use the information when necessary. Political Science has a long tradition of placing citizen decision making into this framework; often models of voting are based on retrospective considerations that are necessarily premised on using memory in this way (Fiorina, 1981). Converse (1964), and Campbell et al. (1960), as well as most of the other authors writing in this area call into whether this approach to information processing is either accurate, or possible.

Indeed the accuracy and use of memory has been the subject of much discussion in the psychological literature, and a number of errors in memory have been identified that are particularly damning to this model of citizen decision making (Schacter, 1999). Research in this area finds that memories are likely to be based on preconceptions, selective use of information, and factually inaccurate. Given these problems expecting that citizens will make correct decisions primarily on the basis of specific retained facts seems extraordinarily unlikely.

The first of Lau and Redlawsk's (1997) alternative information processing constructions remains based on retaining particular information, but acknowledges that information that has been previously adopted into an individual's cognitive process is more likely to be used and used effectively. The process that Lau and Redlawsk refer to as Early Socialization/Cognitive Consistency is closely aligned with the proposals of Converse (1964), Campbell et al. (1960), and Zaller (1992). One of the practical realities of this approach is that partisan identification which has long been identified as a determinant in the political decision making of citizen. This approach is likely one of the political heuristics used by individual citizens and has been ingrained in the cognitive processes citizens use to make political decisions at a relatively early age (Goren, 2005).

The next model identified by Lau and Redlawsk (1997) is what they term "Fast and Frugal Decision Making". This approach which is premised on a limited search for information necessary to make decision making has been operationalized by a number of authors, and asserts that rather than retaining the specifics of any particular instance of information individuals use information when it is freshest to evaluate both the credibility of the information, and that information applies to a myriad of considerations either immediately or in the future. (Lodge, et al., 1995) 
Like "Fast and Frugal Decision Making", bounded rationality is premised on limited information seeking, but unlike the previous methods is not explicitly connected to the use of memory to reach a decision. Instead by using this approach citizens select both the type information they are looking for, and how to use that information based primarily on the decision that is to be made. Once they have identified the necessary information, they apply it to the decision using any one of a plethora of heuristic devices in a near unconscious process. (Lau \& Redlawsk, 2006) In short this approach is differentiated form the "Fast and Frugal Decision Making" because it does not require an active decision making strategy to apply the heuristic to the decision at hand.

Since bounded rationality requires no specific cognition to select the decision process, understanding the heuristic devices that can be automatically applied can provide insight into the decisions made by citizens, including those at the ballot box. These heuristic devices have been well studied by a variety of authors, and have real implications for the potential outcomes of ballot propositions where opinions can become policy directives.

One of the likely starting places for understanding how heuristic devices can alter ballot decisions is through the use of emotion or affect. Much has been made of the ability of emotive decisions to lack rationality. Clearly affect towards a specific policy outcome has the potential to serve as a heuristic device (Rahn, 2000). In particular the effects of anxiety or anger might be of particular importance to a policy decision that has been framed in a particularly negative light. Huddy, Feldman, and Cassese (2008), find that there is a differential response to anxiety, over anger. The former increases the reliance on partisan and other heuristic devices, while anger leads to more use of cognitive processes. Like affect, values have been suggested as a potential decision strategy that shortcuts longer and more complex process (Feldman, 2003).

Potentially, the most important of the heuristic devices, is the use of motivated reasoning. Motivated reasoning, as described in the literature, suggests that individuals have specific, previous preferences, and engage in reasoning processes that are influenced by the previous preferences. (Jost, Glaser, Kruglanski, \& Sulloway, 2003; Taber \& Lodge, 2006) This is most clearly visible when there are repeated iterations of similar decision making. This process essentially shortcuts the decision process by substituting prior preferences for current information about the specifics of time and place. This approach, while certainly parsimonious and systematic, may or may not lead to the correct selection (Rahn, 1993; Redlawsk, 2002).

What seems clear given each of the potential processes for decision-making is two-fold. First, citizens unlike Converse's model do actually use information, and second that that information is likely wrapped up inside a heuristic device. The larger literature on the subject underscores the importance of understanding potential heuristic devices that deliver this information.

One of the objections that can be raised to the use of heuristic devises is that they lose important information that the average citizen is likely use when making political decisions. Heuristic devices are clearly important and relatively accurate descriptions of how citizens make political decisions. However, including those at the ballot box, and operationalizing and explaining the heuristic device researchers may in fact be losing some the information that is actually contained in the device as it is used by individual citizens.

I suggest an alternative heuristic device that citizens may be using to make political decisions, particularly ballot measures regarding taxation, namely their quality of life. Defining what is meant by quality of life is of paramount importance, most measures that attempt to measure quality of life have primarily associated it with the economic conditions that an individual experiences, however a large literature has established that quality of life is not merely economic conditions for the individual although that is an important consideration. Quality of Life must also consider other aspects of daily life that extend beyond the economic realm. (Henderson, Lickerman, \& Flynn, 2000; Yonk, 2011)

\section{Hypotheses}

I expect that for areas exhibiting higher quality of life, it will be easier to pass ballot measures regarding taxation. This central research focus is rooted in social capital literature that indicates where social capital is higher, citizen involvement and cooperation is likewise higher. (Putnam, 2000) I specifically test a series of hypotheses that lead to a clearer answer about the effect of quality of life on decisions to cooperate as measured by agreement with tax issues placed on the local ballot.

H1: Measured Quality of Life will have an identifiable effect on the likelihood of a tax increase ballot measuring passing.

H1A: Higher measured Quality of Life will have a positive effect on the likelihood of a tax increase.

$\mathrm{H} 2$ : Higher measured quality of life will, have an identifiable effect on the total number of yes votes cast in a ballot election even when the population of county is controlled for. 
Again we turn to the predictions of the social capital literature for a theoretical foundation for this hypothesis. The literature predicts and some evidence seems to verify that higher levels of social capital have a positive effect on vote turnout. (Rahn, Brehm, \& Carlson, 1999)

H3A-D: Each of the Components, Quality of Life Indicators will have an identifiable effect on the likelihood of a tax increase ballot measure passing.

Here we return to the theoretic justification earlier explained, as each indicator found in the Quality of Life index measures a distinct area of potential concern for the voting citizen.

\section{Data, Methods and Results:}

Testing for the effect of quality of life requires an operationalization of what specifically we mean by quality of life, and how can it be measured. Defining quality of life is problematic, and numerous definitions have been advanced, I however return to the Calvert-Henderson Definition, which argues that quality of life can only be defined by considering what makes up the world we currently live in, and how that world could be better or worse from the current situation (Henderson, Lickerman, \& Flynn, 2000). This approach has two benefits, first it is easily quantifiable by selecting specific parts of world that can be operationalized and considered, and second it seems to mirror how individuals intuitively consider the world. When using this approach there are two ways of measuring quality of life, the first focuses on the perception of quality held by individual citizens, and second uses objective and clearly measurable indicators. This project is primarily interested in testing the effect of the second way of measuring quality of life on ballot questions about taxation.

In order to test the hypotheses of this project, I constructed a data set consisting of the ballot measures from 223 intermountain west counties from 2006 to 2008 . I also collected a series of potentially relevant indicators that control for the demography and location of our counties of interest. A full list of these variables is found in Table 1.

Table 1. List of variables

\begin{tabular}{l}
\hline Quality of Life Score \\
\hline Economic Development Score \\
Infrastructure Score \\
Health Score \\
Public Safety Score \\
Per Capita Income \\
Wilderness \\
Net Population Change \\
Net Migration \\
Population \\
Education Level \\
Violent Crime(per 1000) \\
Property Crime (per 1000) \\
Federal Expenditure \\
Household Size \\
Percent White \\
Percent Female \\
\hline
\end{tabular}

For a measure of quality of life, I calculated scores for each of four indicators, as well as an overall Quality of Life score. These scores are scaled from 1-100 in each of the indicators and the final score both for the indicators as well as the overall score is calculated using an average of each of the component scores underlying it. This process equally weights both the sub-indicators in calculating the indicator score that are then is equally weighted in creating the overall Quality of Life score. (Yonk 2011) An alternative approach to calculating these scores would require the weighting of the individual data based on some empirical belief about what does or should drive quality of life. Lacking that empirical evidence, I follow the example set by the Economic Freedom of the World Index (2005) and invite those who believe a different weighting is more appropriate to recreate the scores using the appropriate data. (Note 1) (Gwartney, Lawson, \& Norton, 2005) 
To test H1 I ran a Logit regression using as my dependent variable each of the tax related ballot measures across the counties of interest coded as 1 when the ballot tax measure passed. The standard errors for each of the indicators were adjusted for the use of county level data that was combined with the election level data. I tested both the Quality of Life composite score alone (Table 2) and with the other indicators used to calculate the score (Table 3). The second Logit regression tests for the possibility that the effect of the overall Quality of Life score is important only in concert with the individual components measured individually.

Table 2. Quality of Life-Logit

$\mathbf{N}=882$

Percent Correctly Classified 62.93\%

Pseudo R2 .0722

\begin{tabular}{|c|c|c|c|}
\hline Variable & Odds Ratio & Robust Std Error & P Value \\
\hline Quality of Life Score & 1.068 & .0429 & $.100 *$ \\
\hline Per Capita Income & 1.000 & .0002 & .788 \\
\hline Wilderness & 1.229 & .3089 & .412 \\
\hline Net Population Change & 1.000 & .0001 & .146 \\
\hline Net Migration & 9998 & .00004 & $.006 * * *$ \\
\hline Population & 9999 & $1.44 \mathrm{e}-06$ & .769 \\
\hline Education Level & .9895 & .0192 & .589 \\
\hline $\begin{array}{l}\text { Violent Crime } \\
(\text { per 1000) }\end{array}$ & 1.1992 & .0755 & $.004 * * *$ \\
\hline $\begin{array}{l}\text { Property Crime } \\
\text { (per 1000) }\end{array}$ & .9843 & .07553 & .129 \\
\hline Federal Expenditure & 1.0001 & .00001 & $.096^{*}$ \\
\hline Household Size & 1.4825 & .7018 & .406 \\
\hline Percent White & .9883 & .0135 & .393 \\
\hline Percent Female & 1.1303 & .0933 & .138 \\
\hline Federal Lands Percent & .9899 & .0052 & $.053 *$ \\
\hline
\end{tabular}

*significant at the .1 level **significant at the .05 level ***significant at the .01 level

Given the results found in Table 2 I find evidence for H1, and H1A. There is a positive significant relationship between the Quality of Life Score and the probability of yes outcomes on ballot tax measures. The results of this regression are reported as odds ratios so values above one indicate greater likelihood's and those below one indicate lesser likelihoods. My analysis indicates that Net Migration as well as the Percent of Federal lands in a target county have odds ratio's less than one which indicates a reduction in the likelihood that a tax measure will pass, and that Violent Crime measured per 1000 residents and Federal Expenditures have a positive effect on the likelihood of the passage of tax measures.

Adding the component measures to the overall quality of life score makes two important changes to the hypothesis tests from Table 2. First the direction predicted by my hypothesis is reversed. A relationship between quality of life and the likelihood of passing a ballot tax measure exists, but controlling for the component effects, the overall likelihood is decreased. I find that the directional hypotheses for each of the component measures except Public Safety are confirmed. While not significant in this model specification higher values in Public Safety seems to have a negating effect on how quality of life affects ballot decisions. 
Table 3. Quality of Life-Logit with indicators

\begin{tabular}{llll}
\hline \multicolumn{3}{c}{ Percent Correctly Classified 64.17\% } \\
Pseudo R2 .0985
\end{tabular}

*significant at the .1 level **significant at the .05 level ***significant at the .01 level

To test H3 A-D a serious of nine Logit regressions were run, plus the original all-inclusive Logit. One for each of the indicators alone, one for the indicators run together, and one for each indicator with the overall quality of life score included. I have included only the summary of results for each of these regressions in Table 4. This series of tests provides information that is useful in two ways. First the independent effect of each of the indicators is identifiable using this procedure, and second the interaction with the overall Quality of Life score should also be discernable using this procedure.

Looking at Table 4 several variables are immediately obvious as being robust across the variety of specifications, primarily Violent Crimes, Net Migration, and Federal Expenditures all have consistent effects in each of the ten Logit regressions. These consistent effects have interesting implications for future research but have not specific bearing on the hypotheses of this paper.

H3A-D are confirmed only for Economic Development scores and Public Safety. Heath and Infrastructure return insignificant results. These results are the classic definition of mixed. We find support in part and non-support in part as well, clearly the indicators have potential predicative abilities with regards to ballot tax measures but only two of the four tested do so independently.

I then tested the indicators that compose quality of life in concert, and found no significant relationships, meaning that there is no gateway effect that requires the presence of the other indicators. I then tested each of the indicators with the overall Quality of Life score, and again the results are disconfirming; none of the individual indicators are significant even in the presence of the large Quality of Life score. Given these results we return to the fully specified Logit model that includes each of the indicators as well as the overall Quality of Life score. As discussed earlier we find that each of the indicators, excluding Public Safety, as well as the overall score, are significant. Given the totality of the results from the series of regression it appears likely that the relationship between the indicators and the overall score is necessary for the indicators to return significant results. Given Figure 1, this 
result is not surprising Quality of Life alone returns a significant result, and adding the composite measures is likely to return significant results.

Table 4. Quality of Life-Logit, multiple specifications

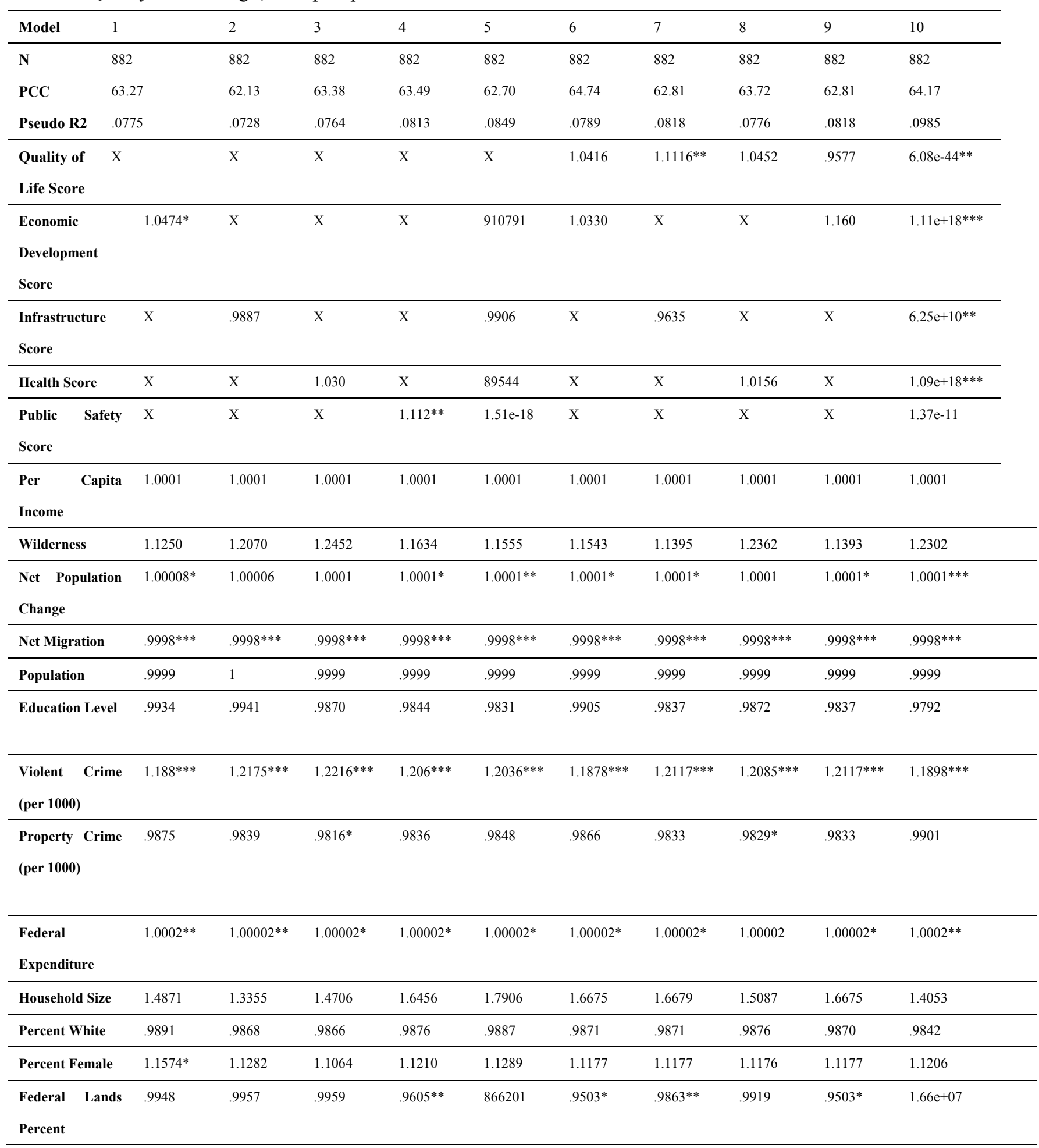

*significant at the .1 level **significant at the .05 level $* * *$ significant at the .01 level

What is somewhat more puzzling is the change in direction of the Quality of Life score, however it seems apparent 
that by including the composite indicators we have parsed out the effect of the indicators and those indicators are explaining the positive variation, and with those things held equal higher values of in the Quality of Life score runs in a direction counter to H1A. This does not necessarily disconfirm H1A out of hand. The goal of including a Quality of Life indicator is primarily to add information that individual citizens might use when deciding how to vote on a specific ballot measure, and as such it is done holistically, not with the variables in isolation. Future studies should consider the possibility that the purpose of the ballot tax measure might activate a different weighting scheme than that used in this model, and might make one of the indicators more important than the others.

My second hypothesis proposes that not only can quality of life have an effect on the outcome of elections but that it can also motivate individuals who support the tax increase to turn and vote in the election. Testing this proposition is relatively straight forward, using a standard OLS regression clustered by county I use the number of yes votes on each of the ballot measures as the dependent variable while controlling for both population and total votes cast, I estimate the effect of Quality of Life on the number of supporters who vote in the ballot election. The results are found in Table 5 .

Table 5. OLS total yes votes regression

\begin{tabular}{llll}
\hline \multicolumn{4}{c}{ N= 883 R-Squared } \\
\hline Variable & Coef & Robust Std Error & P Value \\
Quality of Life Score & -44.506 & 79.4348 & .576 \\
Total Votes Cast & .5363 & .0430 & $.000^{* * *}$ \\
Per Capita Income & -.0293 & .05141 & .569 \\
Population & .0002 & .0175 & .992 \\
Wilderness & 837.857 & 445.5956 & $.061^{*}$ \\
Net Population Change & .826 & .6482 & .204 \\
Net Migration & -1.0773 & .6549 & .101 \\
Education Level & -60.6487 & 46.43013 & .193 \\
Violent Crime(per 1000) & 76.7446 & 137.5841 & .578 \\
Property Crime (per & 7.3438 & 20.3351 & .718 \\
Federal Expenditure & .0318 & .0165 & $.056^{*}$ \\
Household Size & -3932.405 & 1517.931 & $.010^{* * *}$ \\
Percent White & -33.2498 & 16.4762 & $.045^{* *}$ \\
Percent Female & 39.7491 & 71.8741 & .581 \\
Federal Lands Percent & .1074 & 9.645 & .991 \\
Constant & 17674.87 & 11257.56 & .118 \\
\hline
\end{tabular}

*significant at the .1 level $* *$ significant at the .05 level $* * *$ significant at the .01 level

The results from Table 5 indicate that the null hypothesis cannot be rejected for $\mathrm{H} 2$, and as such $\mathrm{H} 2$ is not confirmed.

\section{Implications and Conclusions:}

Given the relatively large number of hypotheses tested in this study, summaries of the results are found in Figure 6. Looking across each of the hypotheses tested we find that when Quality of Life is considered alone it does have an effect that confirms my hypothesis, again when considered alone I find that the direction of the effect is consistent with my theoretical understanding how social capital operationalized as Quality of Life might influence the decision to vote for ballot tax measures. However when considered with the composite indicators the directional hypothesis fails as the direction of the effect is switched. As discussed above, this change in sign is not particularly distressing as the goal of quality of life, as tested in this study, is a full information measure not mitigated by its component parts. Given that goal, the results of the hypothesis test seem to indicate that at some level individual citizens may be using quality of life as a potential heuristic as they make decisions at the ballot box.

This reality is confirmed when average education across counties is considered; in no case did education have a significant effect on the outcome of ballot measures increasing taxes. Clearly something other than knowledge is in 
play as citizens make these decisions. Given the relatively low R2 the results do not conclusively indicate that Quality of Life is the decisive factor, they do however indicate that the Quality of Life as measured in this study has a measurable and significant effect on the outcome of a ballot measure increasing taxes.

Table 6. Summary of hypothesis tests

\begin{tabular}{|c|c|c|c|}
\hline Hypothesis & Description & Confirmed? & Comment \\
\hline H1 & $\begin{array}{l}\text { Quality of Life will have an identifiable } \\
\text { effect on the likelihood of a tax increase } \\
\text { ballot measuring passing. }\end{array}$ & Yes & $\begin{array}{l}\text { Confirmed Independently } \\
\text { and in concert with the } \\
\text { indicators. }\end{array}$ \\
\hline H1A & $\begin{array}{l}\text { Higher measured Quality of Life will } \\
\text { have a positive effect on the likelihood } \\
\text { of a tax increase. }\end{array}$ & $\begin{array}{l}\text { Yes } \\
\text { No }\end{array}$ & $\begin{array}{l}\text { Yes when considered } \\
\text { independently } \\
\text { No when considered with } \\
\text { the indicators }\end{array}$ \\
\hline H2 & $\begin{array}{l}\text { Higher measured Quality of Life will, } \\
\text { have an identifiable effect on the total } \\
\text { number of yes votes cast in a ballot } \\
\text { election when population is controlled } \\
\text { for. }\end{array}$ & No & No relationship exists \\
\hline H3 & $\begin{array}{l}\text { Each of the Components, Quality of Life } \\
\text { Indicators will have an identifiable } \\
\text { effect on the likelihood of a tax increase } \\
\text { ballot measure passing. }\end{array}$ & Mixed & $\begin{array}{lc}2 & \text { Indicators } \\
\text { independent effects }\end{array}$ \\
\hline H3A & $\begin{array}{l}\text { The Economic Development indicator } \\
\text { will have an identifiable effect on the } \\
\text { likelihood of a tax increase ballot } \\
\text { measure passing. }\end{array}$ & Yes & Alone \\
\hline H3B & $\begin{array}{l}\text { The Health indicator will have an } \\
\text { identifiable effect on the likelihood of a } \\
\text { tax increase ballot measure passing. }\end{array}$ & No & \\
\hline $\mathrm{H} 3 \mathrm{C}$ & $\begin{array}{l}\text { The Infrastructure indicator will have an } \\
\text { identifiable effect on the likelihood of a } \\
\text { tax increase ballot measure passing. }\end{array}$ & No & \\
\hline H3D & $\begin{array}{l}\text { The Public Safety indicator will have an } \\
\text { identifiable effect on the likelihood of a } \\
\text { tax increase ballot measure passing. }\end{array}$ & Yes & \\
\hline
\end{tabular}

My other hypothesis do not fare as well as $\mathrm{H} 1$ and $\mathrm{H} 1 \mathrm{~A}, \mathrm{H} 2$ that proposed an increase in voter turnout supporting the ballot measures was not confirmed, and seems to indicate at least in this case the absence of a relationship between Quality of Life and the decision to vote. This result while somewhat disappointing should not have been unexpected; while the social capital literature seems to indicate that a relationship might exist, the relevant literature that tests this proposition is surprisingly scarce, and clearly more research is needed in this area to flesh out the relationship.

My final hypothesis returned mixed results; ideally each of the individual indicators would have had a relationship with the outcome. While this ideal was clearly not met, two of the indicators do return significant results, and should be considered. Both economic development and public safety, which have a long history of being important to voters do have an identifiable effect on ballot measures increasing taxes, in both cases the odds ratio's indicate that the higher the score on both indicators the more likely individuals are to cooperate on taxation issues at the ballot box. It is possible that these two indicators that were related to the ballot propositions specifics, and may be identifying the underlying preferences of the citizens in counties where high indicators scores in these areas were found.

Quality of Life as measured in this study has an effect on citizen decisions about whether to vote for or against a 
ballot measures increasing taxes, and given the literature on how citizens reach these types of decisions, it seems likely that Quality of Life may be being used as a heuristic device as citizens make decisions regarding these measures. Given the results of this study, it appears that using a fuller information heuristic like Quality of Life has the potential to better capture how decisions are being made without the necessity of losing nearly all of the information that citizens intuitively use to make decisions.

If citizens were simply guessing as has been suggested by some, identifying a pattern of passage that is related to quality of life would be nearly impossible to do. Instead using Logit regression to consider the passage of individual ballot measures I find a pattern of results that is statistically related to quality of life and in that pattern is evidence that citizens are using an information process that appears to consider quality of life as they decide how to vote on ballot measures that increase their own taxes.

\section{References}

Campbell, A., Converse, P. E., Miller, W. E., \& Stokes, D. E. (1960). The American Voter. Chicago: The University of Chicago Press.

Converse, P. E. (1964). The Nature of Belief Systems in Mass Politics. In D. E. Apter (Ed.), Ideology and Discontent (pp. 206-261). New York: The Free Press of Glencoe.

Feldman, S. (2003). Values, Ideology, and the Structure of Political Attidues. In D. O. Sears, L. Huddy, \& R. Jervis (Eds.), Oxford Handbook of Political Psychology. Oxford: Oxford University Press.

Fiorina, M. P. (1981). Retrospective Voting in American National Elections. New Haven: Yale University Press.

Goren, P. (2005). Party Identification and Core Political Values. American Journal of Political Science, 882-897. Retrieved from http://www.jstor.org/stable/3647703

Gwartney, J., Lawson, R., \& Norton, S. (2005). Economic Freedom of the World: 2008 Annual Report. Economic Freedom Network. Retrieved from http://www.fraserinstitute.org/WorkArea/DownloadAsset.aspx?id=2690

Henderson, H., Lickerman, J., \& Flynn, P. (2000). Calvert-Henderson Quality of Life Indicators: A New Tool for Assessing National Trends. Bethseda: Calvert Group.

Huddy, L., Feldman, S., \& Cassese, E. (2008). On the Distinct Political Effects of Anxiety and Anger. In W. R. Neumann (Ed.), The Affect Effect (pp. 202-230). Chicago: University of Chicago Press.

Jost, J. T., Glaser, J., Kruglanski, A. W., \& Sulloway, F. J. (2003). Political Conservatism as Motivated Social Cognition. Psychological Bulletin, 1021-1044.

Kuklinski, J. H., \& Quirk, P. J. (2001). Reconsidering the Rational Public: Cognition, Heuristics, and Mass Opinion. In A. Lupia (Ed.), Elements of Reason (pp. 153-182). New York: Cambridge University Press.

Lau, R. R., \& Redlawsk, D. P. (1997). Voting Correctly. American Political Science Review, 585-598. http://dx.doi.org/10.2307/2952076

Lau, R. R., \& Redlawsk, D. P. (2001). Advantages and Disadvantages of Cognitive Heuristics in Political Decision Making. Amerian Journal of Political Science, 951-971. http://dx.doi.org/10.2307/2669334

Lau, R. R., \& Redlawsk, D. P. (2006). How Voters Decide: Information Processing in Electoral Campaigns. Cambridge: Cambridge University Press. http://dx.doi.org/10.1017/CBO9780511791048

Lodge, M., Steenbergen, M. R., \& Brau, S. (1995). The Responsive Voter: Campaign Information and the Dynamics of Candidate Evaluation. The American Political Science Review, 309-326. http://dx.doi.org/10.2307/2082427

Lupia, A. (1994). Shortcust versus Encyclopedias: Information and Voting Behavior in California Insurance Reform Elections. The American Political Science Review, 63-76. http://dx.doi.org/10.2307/2944882

Popkin, S. L. (1991). The Reasoning Voter. Chicago: The University of Chicago Press.

Putnam, R. D. (2000). Bowling Alone: The Collapse and Revival of American Community. New York: Simon \& Schuster.

Rahn, W. (2000). Affect as Information: The Role of Public Mood in Political Reasoning. In A. Lupia (Ed.), Elements of Reason (pp. 130-150). New York: Cambridge University Press.

Rahn, W. M. (1993). The role of partisan stereotypes in information processing about political candidates. American Journal of Political Science, 472-477. http://dx.doi.org/10.2307/2111381

Rahn, W., Brehm, J., \& Carlson, N. (1999). National Elections as Institutions for Generating Social Capital. In T. 
Skocpol, \& M. Fiorina (Eds.), Civic Engagement in American Democracy. Washington D.C.: Brookings Institution Press.

Redlawsk, D. P. (2002). Hot Cognition or Cool Consideration? Testing the Effects of Motivated Reasoning on Political Decision Making. Journal of Politics, 1021-1044. http://dx.doi.org/10.1111/1468-2508.00161

Schacter, D. L. (1999). The Seven Sins of Memory. American Psychologist, 192-203.

Taber, C. S., \& Lodge, M. (2006). Motivated Skepticism in the Evaluation of Political Beliefs. American Journal of Political Science, 755-769. http://10.1111/j.1540-5907.2006.00214.x

Yonk, R. M. (2011). The Political Impact of Quality of Life: Political Science Disserations Georgia State Universtiy Paper 18. http://digitalarchive.gsu.edu/political_science_diss/18

Zaller, J. R. (1992). The Nature and Origins of Mass Opinion. New York : Cambride University Press. http://dx.doi.org/10.1017/CBO9780511818691

\section{Note}

Note 1. This data and the calculations used in scoring each of the relevant counties is available by contacting the author directly at ryanyonk@suu.edu

\section{Copyrights}

Copyright for this article is retained by the author(s), with first publication rights granted to the journal.

This is an open-access article distributed under the terms and conditions of the Creative Commons Attribution license (http://creativecommons.org/licenses/by/3.0/). 